\title{
Women Learning Mathematics: A Qualitative Study
}

\author{
Betsy J. Bannier \\ Departments of Chemistry and Mathematics, Lake Region State College, Devils Lake, North Dakota, United \\ States \\ Email: betsy.bannier@lrsc.edu
}

\begin{abstract}
While research connecting learning and mathematics is relatively abundant, existing research tends to follow a deficit model framework. This qualitative study seeks to identify the ways in which adult women believe they learn mathematics most effectively. Women engaged in fields that are both highly dependent upon mathematical skill and relatively independent of mathematical skill volunteered as participants. Findings reveal that active learning opportunities are perceived as a critical component of learning mathematics, as are the ability and invitation to talk out loud and write freely throughout the learning process. Concrete and logical areas of mathematics, for which real-life connections are often more obvious, are perceived as easier to learn that more abstract and spatial math. In addition, findings suggest that women perceive learning mathematics to be markedly different in adulthood than in childhood. Implications for adult educators engaged in the teaching and communication of mathematical concepts are discussed.
\end{abstract}

Keywords: Mathematics education, math anxiety, tutoring, academic assistance, gender studies, qualitative research.

\section{$1 \quad$ Purpose of the Inquiry}

\subsection{Purpose of the Study}

The purpose of this study was to identify the ways in which adult women believe they learn mathematics most effectively. This purpose was borne from the perspective that research supporting the connections between learning in different mathematics disciplines is limited. Specifically, existing studies tend to employ a deficit-model approach and are primarily limited to identifying student learning difficulties.

\subsection{Research Questions}

This study addressed three primary research questions:

1. How do women perceive their own past and present experiences learning mathematics?

2. What mathematics problem-solving strategies work most effectively for adult women?

3. What mathematics classroom teaching and learning techniques are most effective for adult women?

\subsection{Significance of the Study}

Investigating the ways in which women learn mathematics is important for several reasons. Previous research (Jaworski, 2015; Quintero \& Rosario, 2016) has suggested that mathematical ideas may be better understood if they can be connected to students' existing knowledge. Other mathematics research (Ng, 2016; Postelnicu \& Postelnicu, 2015) has suggested that dichotomies exist in students' thinking of algebraic and calculus-based concepts. Formal definitions and informal knowledge are often disconnected, and concrete examples may be seen as conflicting with formal definitions.

It is widely accepted that each student's knowledge of mathematics is unique. Also, the idea that students make sense of new experiences by adapting or expanding their previous knowledge is generally accepted among researchers in both mathematics (Ernest, 2016; Nesher, 2015) and general learning 
theory (Lui \& Bonner, 2016). Given these positions, a greater understanding of the ways in which women 'make sense' of mathematics may assist educators in accessing and clarifying students' previous knowledge and in helping students to make more meaningful connections to new mathematical material.

\section{$2 \quad$ Inquiry Methods}

\subsection{Design Considerations}

This investigation employed basic qualitative research techniques as described by Rubin and Babbie (2016). Semi-formal interviews were conducted with each of ten participants, described below. Interviews were conducted both face-to-face and electronically, as participants' time and geographic locations allowed. Five initial question sets guided (but did not limit) each interview:

1. How do you learn best?

2. What areas of mathematics have been / are easiest for you to learn? Why? What areas of mathematics have been / are most difficult for you to learn? Why?

3. When you have a particularly challenging mathematics problem to solve, what strategies do you attempt first? Why?

4. Think of how you learn / are learning mathematics as an adult, and compare that with your learning as a child. Is your learning process the same or different? How?

5. Think of the mathematics classroom experiences you have had as an adult. Which classroom teaching and learning techniques seem to work best for you? Why? Which classroom teaching and learning techniques seem ineffective for you? Why?

\subsection{Data Analysis Methods}

The author approached data analysis from the perspective of a transcendental realist. Huberman and Miles (1994) state that

...social phenomena exist not only in the mind, but in the objective world as well, and that there are some lawful, reasonably stable relationships to be found among them. The lawfulness comes from the sequences and the regularities that link phenomena together; it is from these that we derive the constructs that account for individual and social life (p. 182).

In agreement with this statement, data analysis was based upon the premise that a reasonably stable reality exists and can be explained. Interview excerpts were examined and inductively coded to identify patterns and parallels. These patterns and parallels were used to draw conclusions.

Two validity measures were instituted to support the integrity of this study. First, the interview transcripts and preliminary findings were reviewed by a second researcher, who was otherwise not connected with this study. Feedback from the second researcher confirmed logical coding. Second, member checks were requested after the first full draft of this manuscript. Member checks assured that excerpts from interviews were not misrepresented or taken out of context.

\subsection{Participants}

A total of ten college-educated adult women, ranging in age from early 20 s to late 40 s, participated in this study. Nine participants were Caucasian, and one participant was Mexican-American. Five participants were educated in math-intensive fields, while four participants were educated in non-math intensive fields. A tenth participant was originally educated in a non-math intensive field, and through a career change trained for and entered a math-intensive field. All ten of the women selected for this study had acquired extensive experience with self-assessment either through their experiences as students or in their professional development, making them ideal candidates to articulate selfperceptions of their own learning.

Four participants, "Anne, Jane, Olivia, and Alishia" (all names are pseudonyms) were nearing completion of four-year degrees in mathematics; their recent exposure to a variety of upper-level mathematics courses was valuable in comparing and explaining their learning in a variety of mathematics-intensive settings. Anne was a fourth-year, returning adult student in her early 30s, and had been identified by mathematics faculty as remarkably gifted in mathematics. Jane was a traditional 
fourth-year student in her mid-20s and had a diagnosed learning disability that affected her visual and spatial learning. Olivia was a third-year transfer student in her mid-20s, working toward certification and licensure in secondary education mathematics. Alishia, the youngest of the ten interviewees at 20 years old, was a third-year mathematics major.

The fifth interviewee, Elaine, was a middle school mathematics teacher in her late 30s with a Master's degree in education. Catherine, also in her late 30s, earned Master's degrees in two fields that were not math-intensive. In a recent career change, Catherine obtained certification and licensure to teach middle school mathematics.

The final four participants - Patrice, Larissa, Tabitha, and Deann - were all educated and employed in non-math intensive fields. Patrice and Larissa, in their late 30s and late 40s respectively, earned Master's degrees in the humanities and work in higher education. Tabitha, in her early 30s, is a family physician with an emphasis in alternative healing. Finally, Deann, in her mid-20s, recently completed her licensure and certification requirements to teach middle school reading, English, and social studies.

\section{$3 \quad$ Inquiry Results}

\subsection{Findings}

Findings reveal that active learning opportunities are perceived by the study participants as a critical component of learning mathematics, as is the invitation to talk out loud and write freely throughout the learning process. Concrete and logical areas of mathematics, for which real-life connections are often more obvious, are perceived as easier to learn that more abstract and spatial math. In addition, findings suggest that women perceive learning mathematics to be markedly different in adulthood than in childhood.

\subsection{Active Learning Opportunities Are Perceived as a Critical Component of Learning Mathematics}

Pam articulated this point plainly when she explained that she learns best "by doing problems and making lots of mistakes. I always learn the most when I don't get the answer right away." This may be related to Hill's (2001) assertion that, "Emotional states are the link between learning and memory. They are intertwined with reasoning and decision-making. We literally must feel something is true before it can be believed and learned" (in Merriam, 2001, p. 79).

Patrice explained how she always "went to the 'why' right away. I tried to develop a context-based understanding of the situation." Interestingly, this virtually mirrors Marsick and Watkins' (2001) explanation of their Informal and Incidental Learning Model. Marsick and Watkins explained, "the model depicts a progression of meaning making that, in practice, is often more of an ebb and flow as people begin to make sense of a situation" (in Merriam, 2001, p. 29).

Sometimes, active learning means actively perusing seemingly passive materials. For example, Catherine explained how she preferred to "search the web for examples of worked problems rather than ask [her] instructors." Deann stated how she learned best when she felt "able to ask questions without feeling belittled and when...able to explore the material independently, using several formats." It is entirely possible that high achieving women may have more of an emotional response to a task when they feel free to independently struggle with the task temporarily. Hill (2001) explained how "employing multiple sensory experiences helps to activate learning," (in Merriam, 2001, p. 79) but urged educators to remain aware that life experiences make people more diverse as they mature. In teaching mathematics with adult women learners, educators would do well to make independent learning opportunities as abundant and differential as possible.

\subsection{Concrete and Logical Areas of Mathematics Are Perceived as Easier to Master than Abstract and Spatial Areas of Mathematics}

Interviewees offered strong agreement on this matter, repeatedly referring to favoring mathematical topics that are "logical...concrete...not abstract." Differentiation was noted in how interviewees in math- 
intensive fields qualified "logical," compared with how interviewees in non-math intensive fields framed the word. Women in math-intensive fields referred to the presence of theory and equations as logical. Jane, for example, stated that the easiest areas of mathematics for her to learn are "algebra, calculus, and anything theoretical...because it's logical and not spatial." Olivia supported this with her statement that "the easiest areas for me to learn are those involving algebraic formulas." Alishia preferred graphing problems, and explained "once I know what slope, $\mathrm{x}$, and y [are] I am able to use various equations to solve different problems." The definition of advanced mathematical thinking offered by Edwards, Dubinsky, and McDonald (2005), "Thinking that requires deductive and rigorous reasoning about mathematical notions that are not entirely accessible to us through our five senses," (p. 15) fits the explanations made by these women quite well.

For women in non-math intensive fields, mathematics that loaned itself more readily to real-world applications outside of the classroom was perceived as logical. Deann stated that "Fractions and basic geometry principles came pretty easy to me...I could usually figure out the real-world connections of these topics. Larissa explained, "I probably do better with pragmatics of daily life; again, application comes into play. How many square feet of carpet will I need to order, what percent of the bill is paid in tip, etc." Patrice offered an emphatic counterexample,

"The steps of algebraic problem solving made no sense to me whatsoever, and I always found that, in spite of my ability to follow along during class, I had no tools for holding on to the sequencing when I went home. Worse yet, during class, I could never tell that I wouldn't be able to do the work later."

Larissa offered a poignant memory of her difficulties with what she perceived as abstract math, as well as the consequences of those difficulties. When asked to explain which areas of mathematics were most difficult for her to learn, she replied,

...probably the more esoteric aspects of stats, abstract problem solving. Hell, I don't even know what I don't know! I chose not to go into education / education psychology in college because I avoided a stats class by doing so.

These statements should not be surprising. Not only does research into the learning of mathematics (Bryant \& Nunes, 2016) suggest that concrete concepts are easier to master, but research in general learning theory supports this idea as well. As Hill (2001) states,

Learning and memory are context driven. Our brain sorts information depending on whether it is associated with content or context...for best recall, multiple sensory experiences should be employed to code memory with vision, hearing, sound, smell, or movement, and relationships" (in Merriam, 2001, p. 75).

Concrete mathematics, then, would logically be easier to learn since concrete concepts can more readily be placed in a context than abstract concepts. A student may be more likely to successfully situate variables within a tangible context, for example, than they would be likely to successfully situate the abstract concept of a two-dimensional sketch representing a three-dimensional plane. However, both the context and the problem-solving method introduced need to be relevant to the learner. Deann illustrated this point with her recollection,

...advanced algebra has been the most difficult for me to learn. I remember once, a teacher attempted to explain that I might need to know some specific concept if I wanted to be a car mechanic, but I have never really been interested in becoming a car mechanic. Algebra was very time-consuming and stressful to me.

Patrice wholeheartedly agreed with this notion, explaining:

I really seriously disliked being given a topic, such as 'probability,' and them having to watch a bunch of sample problems being worked with no earthly clue as to what was happening and why. Sample problems mean nothing to me until I have a context. The only reason I succeeded in college math was because I worked so hard to develop context.

The measurable impact of the importance of making mathematics contextually relevant should not be underestimated. Research shows that mathematics anxiety in adult women learners is significantly related to the perceived usefulness of mathematics (Jansen, Schmitz, \& van der Maas; 2016).

\subsection{Both Talking Out Loud and Writing Thoughts and Images Are Perceived as Effective Mathematics Problem-solving Strategies}

Interviewees offered a variety of intriguing statements to support this idea. Most interviewees referred to 
the need for writing, talking, or other collaboration. Jane simply laughed when she explained that after thinking about a concept she "starts talking about it." Olivia referred to the need to "draw or construct a picture of what is being asked" - a strategy that Elaine, a trained educator, connected with the Heuristics of Problem Solving. Alishia explained her fondness for group-based problem solving, stating that "being able to work in groups allows individuals to put everyone's ideas out on the table. This way if anyone [is] stuck someone else might be able to help them and vice versa." Tabitha approached her own verbal collaboration indirectly. In discussing her experiences navigating through calculus problems, she explained, "I think I just did it over and over and over again; I seemed to have an 'AHA!' moment. I'm pretty sure a classmate contributed to my 'AHA!' moments."

It is possible that the verbal and written process that each of these interviewees relies upon to solve mathematics problems is an adaptation of the Informal and Incidental Learning Model (Cseh, Watkins, \& Marsick, 1999; in Merriam, 2001, p. 29). The interviewees may be using writing and speech as "triggers" for "interpreting the experience" and "examin[ing] alternative solutions" (in Merriam, 2001, p. 29 ). Elaine expounded upon the need to actively work through alternatives with instructors in her selfreflection.

I need hands-on. I need an instructor who has the ability to read my questions well and if what they are saying isn't clicking with me, I need for them to come from another direction... to really analyze my misunderstanding and work to find the gap in my thinking so that it can be filled with correct information. This is important because filling in gaps in understanding or correcting misunderstanding is at the heart of real understanding.

The pedagogical value of adult women working collaboratively with instructors as well as classmates is supported by Keith (1988), who found that actively encouraging women to ask questions and probe for answers promotes a "constructive struggle" (p. 1) and lessens intimidation. Encouraging women to interact verbally and through their writing may help them to reach a second level of consciousness in mathematics, "extended consciousness," as described by Damasio (1999).

When adult women sense that engaging with mathematics using writing, speech, or collaboration is not welcome in the classroom, they may abandon the pursuit of mathematics altogether. Patrice offered an emphatic example of this, stating.

I never experienced any kind of ownership in algebra-style math. It always seemed as if my kind of brain wasn't welcome there so I took my brain and went over to the arts and humanities, where there's a place for the individual to engage and even challenge the material. As a natural arguer, I've always suspected that my inability to argue math and the lack of encouragement to challenge anything in the types of math classes I've taken were major parts-of-the-hated-whole.

Herzig (2002) acknowledged this all-to-common perception, referring to the perceived lack of interaction in mathematics as "benign neglect." However, if discouraging writing, speaking, and collaboration - which are clearly the preferred modes by which some women learn - is causing women to focus their academic energy elsewhere, then perhaps this lack of interaction is not benign after all.

\subsection{Learning Mathematics as an Adult Is Perceived as Markedly Different from Learning Mathematics as a Child. Larissa and Jane are the Exceptions to this Conclusion}

Larissa confessed to practicing "math avoidance" as both a child and an adult, while Jane stated that her "learning has always been 'weird,' so it's probably the same." Pam, Catherine, and Olivia each stated that learning mathematics as an adult is more difficult, because the level of mathematics being attempted is more complex. Each of the remaining five women interviewed, however, provided detailed explanations of how learning mathematics as an adult seems easier than learning mathematics as a child.

Alishia explained how "As a child, little steps were taken to understand a whole idea. As an adult I feel that the whole idea is introduced first and then you are required to find the steps or develop your own steps to the solution." Patrice expanded upon this idea, explaining,

As a child, I tried to do things my teachers' ways because those were the only methods presented, and I had no way to go outside the box on my own. As an adult, I started college math trying to deal with learning in the same way as in childhood - and at midterm, I had an average of $32 \%$. Because I would do just about anything to never take math again, I worked hard to develop my own theoretical understanding. I used the internet, bought a computer program that had nothing to do with my class or text, and practiced approaching problems in different ways. By the time we reached the final exam, I 
was getting every possible point on every test and assignment. I will never forget my $104 \%$ on the final-I was so proud!

Elaine drew upon her personal experiences as both a learner and an educator when she explained:

What I see now in my field with the adult is a lot more time and attention given to the 'why' of mathematical ideas before the 'how,' which I see as very helpful in increasing my own real understanding. I think that I am learning new mathematics more quickly now than when I used to, but I also have a constant application for it in teaching. I have to analyze student work constantly so I have to figure out where their misunderstandings are and be able to support them out of it. Additionally, I have more background knowledge upon which I am building! Now, for me, it is more important than ever to see the 'why' behind the math.

These vignettes are excellent examples of the differences between the fluid intelligence commonly drawn upon by children in formal classroom settings, and the crystallized intelligence more naturally drawn upon by adults (Carper, 2000). Fluid intelligence, manifested through rapid processing and cycles of memorization and regurgitation, may be so well rehearsed by children in academic environments framed by high-stakes testing that they are unable to "go outside the box," as Patrice remembers. The problem is that abstract and high level mathematics problems do not lend themselves to memorization and regurgitation, as reciting spelling words or key historical dates might. Crystallized intelligence, often manifested through a verbal analysis of the problem at hand in reference to accumulated life experiences, may be a more appropriate tool.

Throughout their memoirs of learning mathematics as both a child and an adult, participants emphasized the importance of both pacing and relevance of content. Catherine explained her preference as an adult to "work through things in the book at my own pace. Other people in the class are usually faster or slower than I am and it annoys me with things not moving at my pace. I prefer individual study." Larissa, in contrast, felt that application-based learning is paramount as an adult. She described how

"Now that I see stats in practice in the research I read, I am much more curious about how to set up a problem to yield statistically significant results...I could probably come up with questions I am curious about from a professional perspective that would give me the context to persevere through the hell of my ignorance."

Finally, it is worth noting that two of the women interviewed made reference to being able to use calculators as adults. Tabitha stated, "I use a calculator any time I need to calculate a drug dosage, which is really the only time I do math [now]." Deann expressed her frustration in this arena, stating "I never understood why teachers instructing complex math skills wouldn't allow calculators - in the real world, there are calculators." While the purpose of this article is not to debate the use of calculators in the mathematics classroom, the references of interviewees to this issue warrant consideration in at least a general sense. Forcing adult women to "learn" mathematics sans calculators, which in turn forces learners to rely upon fluid intelligence rather than crystallized intelligence (Readers, when is the last time you balanced your checkbook without a calculator?), may create a very real and unnecessary barrier to learning. For what purpose? Edwards, Dubinsky, and McDonald (2005) profess that

"Exemplary mathematical thinking may occur at any age of student and level of mathematics, but the particular notion that we describe as advanced mathematical thinking occurs only under certain conditions involving rigorous and deductive reasoning about mathematical objects that are unavailable to our five senses" (p. 24).

For adult learners in particular, using a calculator for basic operations may serve as a reinforcement of experience-induced crystallized intelligence, allowing more advanced mathematical thinking to naturally occur.

\section{Implications and Future Directions}

Several clear implications for educators of adult women mathematics learners can be drawn from the findings of this study. First, if learners perceive active learning opportunities as critical, mathematics educators should work diligently to build active learning opportunities into the structure of their courses. This task is not as straightforward as one might initially assume. Combining the wonderful diversity of adult learners with both the research suggesting that adults draw primarily upon crystallized intelligence 
in their formal learning and the finding that adult learners value applications in authentic, relevant contexts most highly, one can begin to see how dynamic and divergent such active learning opportunities must truly be in order to maximize learning outcomes.

Second, if concrete and logical areas of mathematics are perceived as being easier to learn, then connections to concrete and logical areas should also be offered in courses that primarily emphasize abstract and spatial learning outcomes. The burden of this task need not lie solely on the educator. Rather, the need for concrete and logical connections might be connected to the third need identified in this study, below, by encouraging adult learners to investigate, discuss, and write about these connections.

Third, if talking out loud and writing thoughts and images are perceived as effective problem-solving strategies, then opportunities for dialogue and free writing should be built into mathematics class sessions. For women in particular, this might begin with a completely innocuous but genuine verbal question such as, "What brings you to this class?" Research shows that women value being perceived as collaborators in mathematics classrooms (Keith, 1988), and that significant numbers of women are drawn to learn mathematics as an adult in order to support their children's academic endeavors (Brew, 2001). Mathematics educators should be aware that female learners tend to speak more freely in singlegender mathematics learning environments (Simpson, 2015), and that allowing the use of everyday language rather than academic jargon has been shown to help women achieve success in mathematics (Drew, 2015).

Fourth, if learning mathematics as an adult is perceived to be markedly different than learning mathematics as a child, then mathematics educators must realize that extrapolating common K-12 teaching and learning techniques to the collegiate classroom may be woefully ineffective. Much work remains to be done in this arena. At a minimum, mathematics educators might consider administering one of the many, widely available learning styles assessments such as Kolb or LASSI, and then counseling students on their results. While this gesture would provide educators and learners alike with a frame of reference for creating appropriate learning experiences, the very concept of "learning styles" tends to build upon conventional classroom settings as its frame of reference. A more comprehensive approach might be to draw upon a combination of feminist theory and critical race theory to deconstruct conventional teaching and learning modes, as well as testing and measuring modes, altogether (Banks, 2006; Gillborn, 2006). This would undoubtedly be a daunting, largely uncharted undertaking, but the results may be rewarding indeed.

The time is long overdue to stop approaching adult women mathematics learners through a deficitmodel lens. Rather than trying to figure out what's "wrong" with how women make sense of mathematics, researchers and practitioners alike would do well to celebrate the reality that many women are dynamic, active mathematics learners who value myriad learning opportunities and concrete, authentic contexts. We must adjust the lens of mathematics teaching and learning theory to meet the needs of adult women learners, without judgment and with haste.

\section{References}

1. J. Banks (2006), "Democracy, diversity, and social justice: Educating citizens for the public interest in a global age," In G. Ladson-Billings and W. Tate, Eds., Education research in the public interest: Social justice, action, and policy. Teachers College Press.

2. C. Brew (2001) "Implications for women and children when mothers return to study mathematics," In M. J. Schmitt and K. Safford-Ramus, Comps., Adults Learning Mathematics-7: A conversation between researchers and practitioners. Harvard University.

3. P. Bryant and T. Nunes, Eds. (2016), Learning and teaching mathematics: An international perspective. Psychology Press.

4. J. Carper (2000), Your miracle brain. HarperCollins.

5. M. Cseh, K. E. Watkins, and V. J. Marsick (1999), "Re-conceptualizing Marsick and Watkins' Model of Informal and Incidental Learning in the Workplace," In K. P. Kuchinke, Ed., Proceedings, Academy of Human Resource Development Conference, Volume I. Academy of Human Resource Development.

6. A. Damasio (1999), The feeling of what happens: Body and emotion in the making of consciousness. Harcourt Brace. 
7. D. E. Drew (2015), STEM the tide: Reforming science, technology, engineering, and math education in America. JHU Press.

8. B. S. Edwards, E. Dubinsky, and M. A. McDonald (2005), "Advanced mathematical thinking," Mathematical thinking and learning, vol. 7, no. 1, pp. 15-25.

9. P. Ernest (2016), "Values and mathematics: Overt and covert," Culture and dialogue, vol. 4, no. 1, pp. 48-82.

10.D. Gillborn, (2006), "Public interest and the interests of white people are not the same: Assessment, education policy, and racism," In G. Ladson-Billings and W. Tate, Eds., Education research in the public interest: Social justice, action, and policy. Teachers College Press.

11.A. Herzig (2002), "Talking the talk: Graduate women in the disciplinary culture of mathematics," Paper presented at the Annual Meeting of the American Educational Research Association. ERIC Document Reproduction Service Number ED466633

12.A. Herzig (2002), "Talking the talk: Graduate women in the disciplinary culture of mathematics," Paper presented at the Annual Meeting of the American Educational Research Association. ERIC Document Reproduction Service Number ED466633

13.L. Hill (2001), "The brain and consciousness: Sources of information for understanding adult learning," In S. Merriam, Ed., The new update on adult learning theory. Jossey-Bass.

14.M. Huberman and M. B. Miles (1994), Qualitative data analysis: An expanded sourcebook. Sage Publications.

15.B. R. Jansen, E. A. Schmitz, and H. L. van der Maas (2016), "Affective and motivational factors mediate the relation between math skills and use of math in everyday life," Frontiers in psychology, vol. 7.

16.B. Jaworski (2015), "Intersubjectivity in mathematics teaching: Meaning-making from constructivist and/or sociocultural perspectives?" In Shifts in the field of mathematics education. Springer Singapore.

17.S. Keith (1988), "Women and communication in mathematics: One woman's viewpoint," Paper presented at the Annual Meeting of the National Women's Studies Association. ERIC Document Reproduction Service Number ED298583

18.A. M. Lui and S. M. Bonner (2016), "Preservice and inservice teachers' knowledge, beliefs, and instructional planning in primary school mathematics," Teaching and Teacher Education, vol. 56, pp. 1-13.

19.V. Marsick and K. Watkins (2001), "Informal and incidental learning," In S. Merriam, Ed., The new update on adult learning theory. Jossey-Bass.

20.S. Merriam (2001), "Andragogy and self - directed learning: Pillars of adult learning theory," New directions for adult and continuing education, vol. 89, pp. 3-14.

21.P. Nesher (2015), "On the diversity and multiplicity of theories in mathematics education," Pursuing excellence in mathematics education. Springer International Publishing.

22.O. L. Ng (2016), "Comparing calculus communication across static and dynamic environments using a multimodal approach," Digital experiences in mathematics education.

23.V. Postelnicu and F. Postelnicu (2015, February), "College students' understanding of parameters in algebra," In CERME 9-Ninth Congress of the European Society for Research in Mathematics Education.

24.A. H. Quintero and H. Rosario (2016), Math Makes Sense!: A Constructivist Approach to the Teaching and Learning of Mathematics. World Scientific.

25.A. Rubin and E. R. Babbie (2016), Empowerment Series: Research Methods for Social Work. Cengage Learning.

26.A. Simpson (2015), Kaleidoscopic View of Voices Shaping Female and Male Adolescents' Dynamic Mathematics Identity within Single-Sex and Coeducational Environments. Clemson University. Available: http://tigerprints.clemson.edu /all_dissertations/1532/ 